\title{
Geomorphometric Analysis of Raster Image Data to Detect Terrain Ruggedness and Drainage Density
}

\author{
Marco Moreno, Serguei Levachkine, Miguel Torres, and Rolando Quintero \\ Geoprocessing Laboratory-Centre for Computing Research-National Polytechnic Institute, \\ Mexico City, Mexico \\ \{marcomoreno, palych, mtorres, quintero\}@cic.ipn.mx \\ http://geo.cic.ipn.mx, http://geopro.cic.ipn.mx
}

\begin{abstract}
We present an approach to identify some geomorphometrical characteristics of raster geo-images. The identification involves the generation of raster layers, topographic ruggedness and drainage density. The topographic ruggedness is used to express the amount of elevation difference between adjacent cells of Digital Elevation Model (DEM). The topographic ruggedness is presented by means of Terrain Ruggedness Index (TRI). The densities layers are obtained by Spline Interpolation Method. These layers are used to represent the amount of geographic linear objects. The algorithm has been implemented into Geographical Information System (GIS) - ArcInfo, and applied for a GIS of Tamaulipas State, Mexico.
\end{abstract}

\section{Introduction}

Geomorphometric analysis is the measurement of geometry of the landforms in raster images and has traditionally been applied to watersheds, drainages, hillslopes and other groups of terrain objects. In particular basin morphometric parameters attracted much attention from hydrologists and geomorphologists since watersheds have been used for analysis of different physical ecosystem processes [1]. The geomorphometry represents one set of recommended variables to analyze distribution and concentration of certain spatial objects.

Nowadays, Geographical Information Systems are powerful and useful tools as means of information, visualization and research or as decision making applications [2]. However, contrasting with the traditional topographic map methods, the GIS methods are relatively easy to apply in a consistent way on large areas of landscape, because they allow summation of terrain characteristics for any region. They can be used to provide geomorphometric data and therefore insight the processes affected by terrain morphology for all types of mapping.

Since the mid-1980s, with increasing popularity of GIS technology and availability of Digital Elevation Models (DEM), the potential of using DEM in studies of surface processes has been widely recognized [3]. New methods and algorithms have been developed to automate the procedure of terrain characterization [4]. DEM has been 
used to delineate drainage networks and watershed boundaries to compute slope characteristics, and to produce flow paths [5]. In addition, DEM has been incorporated in distributed hydrological models [6].

DEM is playing an increasingly important role in many technical fields of GIS development, including earth and environmental sciences, hazard reduction, civil engineering, forestry, landscape planning, and commercial display. It is difficult to exaggerate the importance of the DEM to geomorphology, because DEM may ultimately replace printed maps as the standard means of portraying landforms. The contour maps remain an important data source for DEM, although techniques for measuring elevation directly from satellite images have been introduced in recent years. Tamaulipas State area is covered by DEM at two resolutions, $50 \times 50 \mathrm{~m}$ and $250 \times 250 \mathrm{~m}$ [7].

In this paper, we propose a method to make spatial analysis based on geo-image processing by means of Spatial Analyzer Module (SAM). In Section 2 we present the description of SAM and describe its functionality. In the next sections, we describe how terrain ruggedness and drainage density have been obtained. Some results are shown in Section 5. Section 6 presents our conclusions.

\section{Spatial Analyzer Module}

SAM is a special module, which has been designed to make spatial analysis procedures. SAM uses vector and raster data to make the spatial analysis. This module has been implemented using Arc Macro Language (AML) to ensure portability between computer platforms executing ArcInfo 7.0 or later.

The analysis is based on using different spatial data related to the case of study. SAM contains two components: Analysis Block and List of Procedures. 1) Analysis Block is composed of a set of processes to make data analysis. 2) List of Procedures stores the sequence of steps to execute the processes [8] (see Fig. 1).

\begin{tabular}{|c|c|c|c|}
\hline \multicolumn{4}{|l|}{ SAM } \\
\hline \multicolumn{4}{|c|}{ Analysis Block } \\
\hline $\begin{array}{c}\text { Interpolate } \\
\text { Function }\end{array}$ & $\begin{array}{c}\text { Grid } \\
\text { Functions }\end{array}$ & $\begin{array}{c}\text { Grid } \\
\text { Generator }\end{array}$ & $\begin{array}{l}\text { Overlay } \\
\text { Function }\end{array}$ \\
\hline \multirow{2}{*}{\multicolumn{4}{|c|}{$L_{-------------------------------1}$}} \\
\hline & & e List & \\
\hline
\end{tabular}

Fig. 1. Spatial Analyzer Module is composed of Analysis Block and Procedure List

\subsection{Analysis Block}

It contains the functions to make spatial analysis. These functions are the following:

Interpolate Function. The method used is a minimum curvature spline in two dimensions from a set of points. For computational purposes, the entire space of the output grid is divided into blocks or regions of equal size. They are represented in a rectangular shape. The equation 1 shows the spline function that has been used [9]: 


$$
S(x, y)=T(x, y)+\sum_{j=1}^{N} \lambda_{j} R\left(r_{j}\right),
$$

where $\mathrm{j}=1,2 \ldots \mathrm{N} ; \mathrm{N}$ is the number of points; $\bullet$ are the coefficients obtained from the system of equations, which computes the point coordinates; $R\left(r_{j}\right)$ is the distance from the point $(\mathrm{x}, \mathrm{y})$ to the $\mathrm{j}^{\text {th }}$ point.

To use this function, it is necessary to provide the set of points and tolerances, which depend on the specific case of study.

Grid Functions. They contain the set of functions for cell analysis that include operations of the map algebra, and describe how the operations are specified, the data to operate on, and the order in which operations should be processed. In this case the function is SQRT. SQRT calculates the square root of the input grid [10].

Grid Generator. It is used to process some analyzed data, especially in density map generation. The vector grids are regular of $m \times m$ magnitude, in which $m$ is the cell size. The cell magnitude in the grid is determined by the phenomenon under study characteristics (scale and covered area). Two alternatives can be used to generate the grids. First, specifying the initial and terminal grid coordinates $\left(\left(\mathrm{x}_{0}, \mathrm{y}_{0}\right),\left(\mathrm{x}_{1}, \mathrm{y}_{1}\right)\right)$ respectively and establishing the number of required divisions for the grid. The second alternative is to specify the initial coordinate $\left(\mathrm{x}_{0}, \mathrm{y}_{0}\right)$, cell size, number of columns and rows in the grid [11] (Fig. 2).

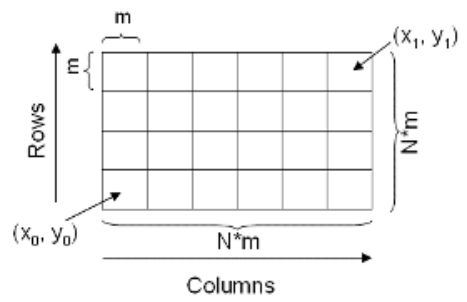

Fig. 2. Specifications of the grid

Overlay Functions. This module has been designed to make topological overlays, which can be used to identify areas of risk. A set of operations has been defined, and applied to the spatial analysis. This is made to establish the conditions and to combine different information layers using logical operators. These functions combine spatial and attribute data. The implemented operations for topological overlay in this application are: intersection, union and identity, which are represented by the symbols $\cap, \cup$ and I respectively [10].

\subsection{List of Procedures}

It stores the set of procedures for each one of the analysis processes. It has a description of the required data type and the restrictions. However, the users can change the selection criteria. This provides a list of functions as an alternative for the analysis, in 
which the parameters can be modified. SAM has a wide range of applications, not only to make geomorphometric analysis. It is also possible to perform the detection of landslide and flooding areas [11].

\section{Generation of Topographic Ruggedness Layer}

The Terrain Ruggedness Index (TRI) is a measurement developed by Riley to represent the amount of elevation difference between adjacent cells of a digital elevation grid [12]. The process essentially computes the difference in elevation values from a center cell and the eight cells surrounding it immediately. Then it squares each of the eight elevation difference values to make them all positive and averages the squares. The terrain ruggedness index is then derived by taking the square root of this average, and corresponds to average elevation change between any point on a grid and its surrounding area. The authors of the TRI propose the classification for the values obtained for the index (Table 1):

Table 1. Terrain Ruggedness Index Classification

\begin{tabular}{ccc}
\hline TRI & Interval $(\mathbf{m})$ & Represent \\
\hline 1 & $0-80$ & Level terrain surface \\
2 & $81-116$ & Nearly level surface \\
3 & $117-161$ & Slightly rugged surface \\
4 & $162-239$ & Intermediately rugged surface \\
5 & $240-497$ & Moderately rugged \\
6 & $498-958$ & Highly rugged \\
7 & $959-4367$ & Extremely rugged surface \\
\hline
\end{tabular}

The pseudo-code [12] to generate TRI layer is:

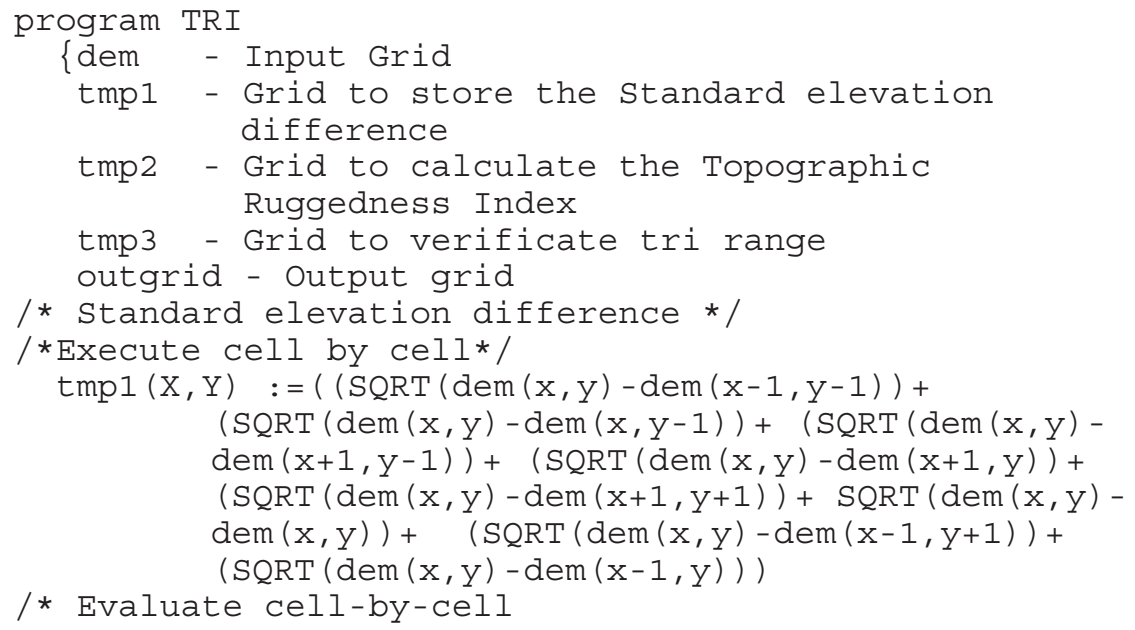




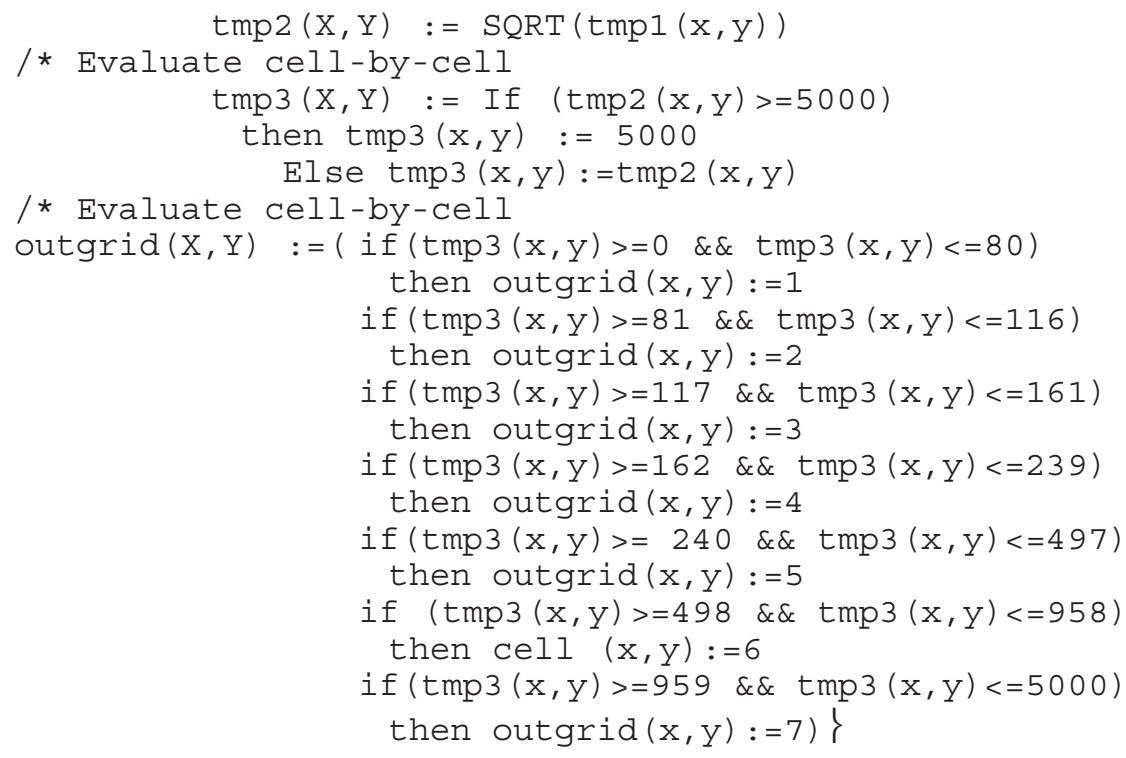

\section{Generation of Drainage Density}

Drainage density is defined as the total length of channels divided by area and measured the degree to which a landscape is dissected by channels [13]. To generate the drainage density layer, it is necessary to build a regular grid of $1 \mathrm{~km}^{2}$ per cell [14]. Using this layer, we can construct the centroid layer. Later, the drainage layer is intersected with the grid layer. For each cell of the grid the lengths by area unit are added into centroid layer. The centroid layer is interpolated and the drainage density layer is obtained. Fig. 3 shows the process to generate the drainage density layer.

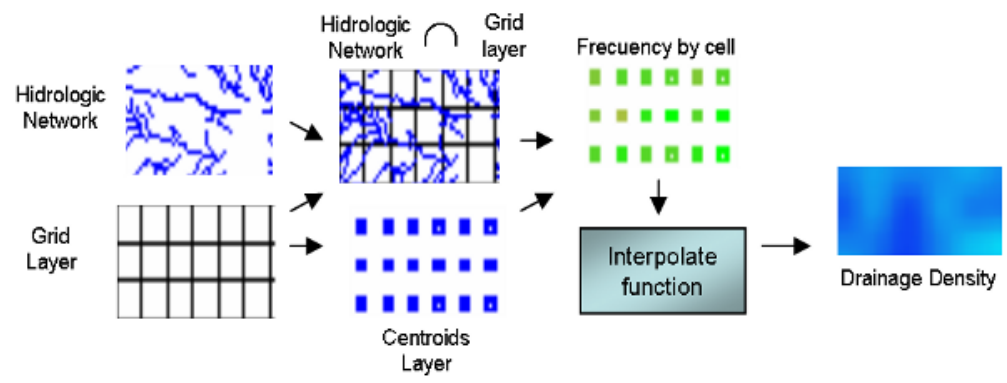

Fig. 3. Process to generate the drainage density layer 


\section{Results}

Using SAM, we construct drainage density and terrain ruggedness layers. The method has been applied to the Tamaulipas State, Mexico. Some results are presented in this section.

Fig. 4a shows the original DEM. The minimum value is $0 \mathrm{~m}$, maximum value is 3496, mean value of this layer is $227.40 \mathrm{~m}$ and the Standard Deviation is 498.469. Fig. $4 \mathrm{~b}$ shows the Terrain Ruggedness layer constructed by SAM, and the TRI classification of this area. The terrain index layer has the following values; mean is $2.386 \mathrm{~m}$ and the Standard Deviation is 2.457. This means that Tamaulipas State has slightly rugged areas in its territory. The extremely rugged areas are principally concentrated at the southwestern part of Tamaulipas State. DEM and TRI Layers are composed by 8000 rows and 2478 columns.

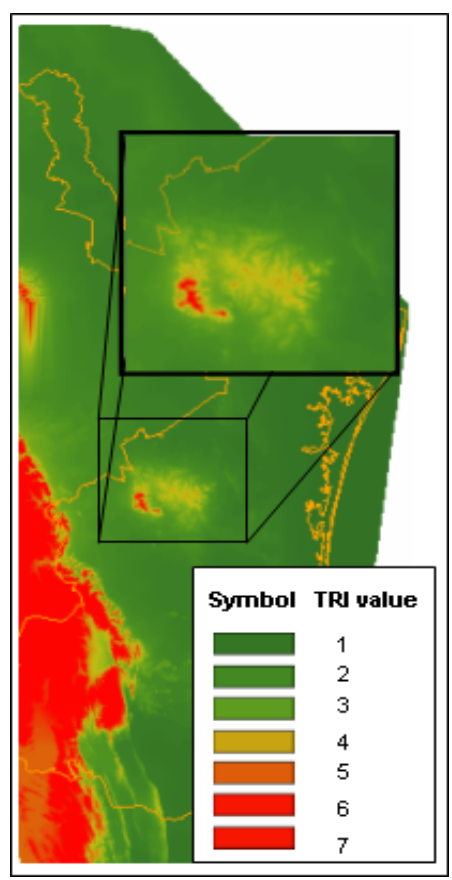

a)

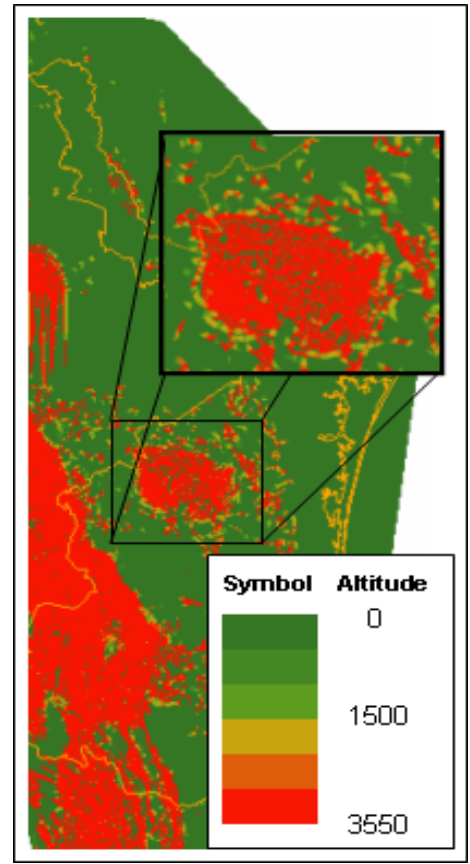

b)

Fig. 4. a) Digital Elevation Model, b) Terrain Ruggedness layer.

Fig. 5a shows the hydrological layer, this layer contains all streams of Tamaulipas State $(1: 200,000)$. The drainage density layer is showed in Fig. 5b. The mean value of this layer is 24857 , which is nearly to the lower value. The concentrations are represented in blue scale, the dark blue represents higher concentrations and light blue represents the lower concentrations. We can see the highest concentrations of drainage are situated in the south coast, near Tampico City. While the lowest density are presented in the northwestern part of Tamaulipas State. 


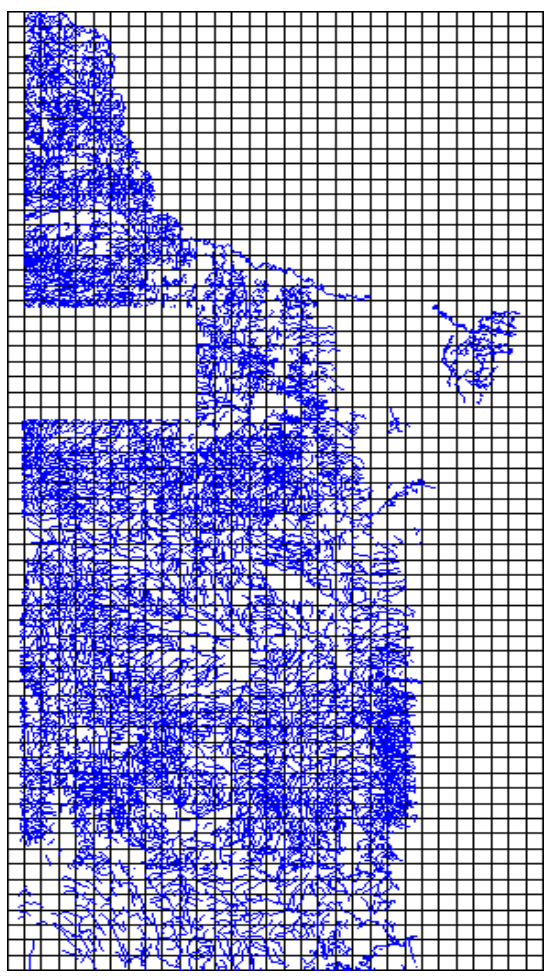

a)

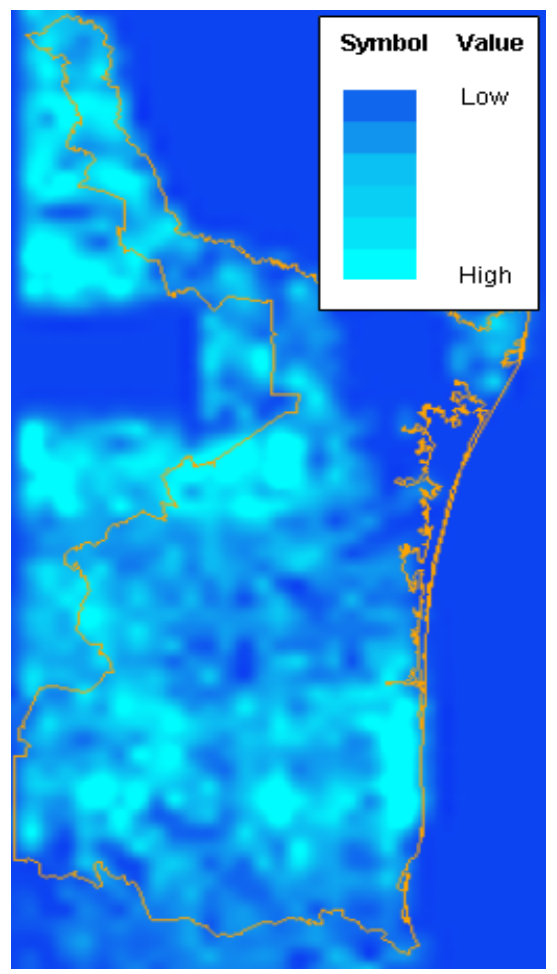

b)

Fig. 5. a) Hydrological Layer, b) Drainage Density

\section{Conclusion}

In this work, a GIS-application (SAM) has been developed to analyze geomorphometric characteristics of geo-images. SAM detects drainage density and terrain ruggedness using raster image data. In this method, spatial and attribute data are used to generate raster data. Using SAM, it is possible to define the semantic importance of the characteristics of the spatial data. Users can modify the criteria to have different scenarios to improve the decision making process.

The geomorphometric analysis is traditionally performed using the methods based on topographic map-processing in manual way. Our approach significantly decreases the amount of time and effort required to quantify selected terrain characteristics. Other methods are designed to evaluate additional characteristics, which are different to the properties proposed in our approach. However, these methods can be integrated into SAM.

The generation of drainage density and terrain ruggedness layers facilitates the extraction of spatial characteristics that can be used in other cartographic processes, for instance in the generalization. 
Acknowledgments. The authors of this paper wish to thank the Centre for Computing Research (CIC-IPN), General Coordination of Postgraduate Study and Research (CGEPI), National Polytechnic Institute (IPN) and the Mexican National Council for Science and Technology (CONACYT) for their support.

\section{References}

1. Bonk, R: Scale-dependent Geomorphometric Analysis for Glacier Mapping at Nanga Parbat: GRASS GIS Approach, Proceedings of the Open source GIS - GRASS User's conference 2002, Italy (2002)

2. Goodchild, M.: Perspective: Browsing metadata, where do we go from here?: Vol. 10 Geo Info Systems (2000) 30-31

3. Wharton, G.: Progress in the use of drainage network indices for rainfall-runoff modelling and runoff prediction. Progress in Physical Geography, Vol. 18 (1994) 539-557

4. Desmet, P.J.J., and Govers, G.: Comparison of routing algorithms for digital elevation models and their implications for predicting ephemeral gullies. International Journal of Geographical Information Systems, Vol. 10 (1996) 311-331

5. Wiche, G. J., Jenson, S. K., Baglio, J. V., and Dominguez, J. O.: Application of digital elevation models to delineate drainage areas and compute hydrologic characteristics for sites in the James River Basin, North Dakota, U.S. Geological Survey Water-Supply Paper, Vol. 23 (1992)

6. Garrote, L., and Bras, R. L.: A distributed model for real-time flood forecasting using digital elevation models. Journal of Hydrology, Vol. 167 (1995) 279-306.

7. Instituto Nacional de Geografía Estadística e Informática (INEGI): Modelos Digitales de Elevación - Generalidades y Especificaciones, INEGI (1999)

8. Torres, M., Moreno, M., Menchaca, R. and Levachkine, S.: Making Spatial Analysis with a Distributed Geographical Information System, Series on APPLIED INFORMATICS AI 2003, International Conference on Databases and Applications (DBA'2003), International Association of Science and Technology for Development (2003) 1245-1250

9. Mitas, L. and Mitasova, H.: General Variational Approach to the Interpolation Problem, Journal of Computers and Mathematics with Applications, Vol. 16 (1988) 983-992

10. Molenaar,, M.: An Introduction to the theory of spatial object modelling for GIS. Taylor \& Francis, U.K. (1998)

11. Torres, M., Moreno, M. and Levachkine, S.: SIGETAM: Herramienta GIS de Escritorio enfocada a la Detección de Zonas de Riesgo de Deslave e Inundación, 1st International Congress of Informatics and Computing, Guadalajara, México (2002) 156-168

12. Riley, S. J., DeGloria, S. D., and Elliot, R.: A terrain ruggedness index that quantifies topographic heterogeneity. Intermountain Journal of Sciences, Vol. 5 (1999) 23-27

13. Horton, R. E.: Drainage basin characteristics, Transactions American Geophysical Union, Vol. 13 (1932) 350-361.

14. Tarboton, D. and Ames, D: Advances in the mapping of flow networks from digital elevation data, World Water and Environmental Resources Congress, Florida, (2001) 